Article

\title{
A 'Hands on' Public Service Program to Help People Stay Sober and Safer on the Roadway
}

\author{
Jessica Andrews ${ }^{1}$, Zanab Shareef ${ }^{1}$, Mohammed Mohammed ${ }^{1}$, Edison Nwobi ${ }^{1}$, Tariq Masri-zada ${ }^{1}$, \\ Tyiesha Head ${ }^{1}$, Tylor Zohr ${ }^{1}$, Doreen Head ${ }^{2}$ and Randall Commissaris ${ }^{1, *}$ \\ 1 Department of Pharmaceutical Sciences, Eugene Applebaum College of Pharmacy and Health Sciences, \\ Wayne State University, Detroit, MI 48202, USA; Jessica2andrews@wayne.edu (J.A.); \\ zanab.shareef@wayne.edu (Z.S.); mohammed.mohammed@wayne.edu (M.M.); \\ Edison.nwobi@wayne.edu (E.N.); tariq.masri-zada@udm.edu (T.M.-z.); Tyiesha.head@udm.ord (T.H.); \\ Tylor.zohr@wayne.edu (T.Z.) \\ 2 Department of Clinical Sciences, Eugene Applebaum College of Pharmacy and Health Sciences, \\ Wayne State University, Detroit, MI 48202, USA; Doreen.head@wayne.edu \\ * Correspondence: Commissaris@wayne.edu
}

check for updates

Citation: Andrews, J.; Shareef, Z.; Mohammed, M.; Nwobi, E.; Masri-zada, T.; Head, T.; Zohr, T.; Head, D.; Commissaris, R. A ‘Hands on' Public Service Program to Help People Stay Sober and Safer on the Roadway. Sustainability 2021, 13, 10979. https://doi.org/10.3390/ su131910979

Academic Editor: Salissou Moutari

Received: 24 July 2021

Accepted: 26 September 2021

Published: 3 October 2021

Publisher's Note: MDPI stays neutral with regard to jurisdictional claims in published maps and institutional affiliations.

Copyright: (c) 2021 by the authors. Licensee MDPI, Basel, Switzerland. This article is an open access article distributed under the terms and conditions of the Creative Commons Attribution (CC BY) license (https:// creativecommons.org/licenses/by/ $4.0 /)$.

\begin{abstract}
Despite the existence of many different "Don't drink and drive" programs and campaigns over the past 30 years, alcohol intoxication has continued to account for approximately one quarter to one third of all traffic crashes and crash-related deaths in the United States. The present study describes a new 'hands on' evidence-based approach involving real alcohol-intoxicated subjects using a virtual reality (VR) driving 'game' to educate the public more effectively about the dangers of drunk driving. A single demonstration subject 'drove' a VR-based portable driving simulator on multiple occasions before (Pre) and at 30 min intervals for up to six hours after either vehicle (no alcohol), two, four or six 'drinks' (3,6, or 9 ounces of 80 proof vodka). The defensive driving task was a choice reaction crash avoidance steering maneuver in which the driver's task was to determine which way to turn to avoid a crash and then aggressively steer away to avoid a crash. The primary dependent variable was the latency to initiate an avoidance steering response. Blood alcohol concentration (BAC) determinations (estimations) were conducted immediately prior to driving tests using BAC Track portable breathalyzers. Control drives (Pre-Treatment and Vehicle treatment) were characterized by an approximately 300-320 ms reaction time to initiate a crash avoidance. Alcohol increased crash-avoidance reaction time. Peak BAC values were 35, 78 and $120 \mathrm{mg} / \mathrm{dL}$ for two, four and six drinks, respectively; the decline in BAC was comparable and linear for all three treatments. There was a strong correlation $(\mathrm{r}=0.85)$ between pre-drive BAC level and reaction time across all of the alcohol-related drives. There was a significant increase in crash avoidance reaction time when the BAC was $50-79 \mathrm{mg} / \mathrm{dL}$, which is below the legally defined BAC limit $(80 \mathrm{mg} / \mathrm{dL})$ currently used in most states in the US. These results demonstrate that (1) this VR-based driving simulator task could be a useful 'hands on' tool for providing public service demonstrations regarding the hazards of drinking and driving and (2) a BAC concentration of $50 \mathrm{mg} / \mathrm{dL}$ represents a reasonable evidence-based cut-off for alcohol-impaired driving.
\end{abstract}

Keywords: alcohol; driving; driving simulator; drunk driving; impaired driving; road safety; drunk driving prevention; alcohol legal limit

\section{Introduction}

Drunk driving continues to be a significant cause of highway crashes and deaths. If there is any good news with respect to drunk driving, it is that there has been a significant decline in drunk driving-related deaths over the past 40 years or so. In the early 1980s, nearly $45-50 \%$ of crash-related fatalities involved a driver with a BAC $>80 \mathrm{mg} / \mathrm{dL}$ (aka $0.08 \%$ ), whereas today that figure has been cut significantly, with approximately $30 \%$ of the crash-related fatalities involving drivers with a BAC $>80 \mathrm{mg} / \mathrm{dL}([1,2]$. Several factors 
likely contributed to this decline. Legislative changes like the National Drinking Age Act of 1984 [3] and the National $80 \mathrm{mg} / \mathrm{dL}$ BAC Cut-Off Act [4] have contributed significantly, as have the use of breathalyzer-dependent ignition lock-out devices [5,6] and sobriety checkpoints in states where they are allowed [7-9]. In addition, advocacy/awareness groups such as Mothers against Drunk Driving [10], Students Against Destructive Decisions [11] and Designated Driver campaigns [12] have likely had a significant positive effect. Many public service announcements, like "Friends don't let friends drive drunk", "Be sober or get pulled over", have likely had an impact as well [13]. Finally, improvements in car and road conditions have contributed greatly.

Despite the positive effects of these various initiatives to reduce drunk driving deaths from the levels of the early 1980s, messaging from the alcohol industry has continued to (mis)inform public health policy [14], with one result being that alcohol-related traffic deaths have nonetheless remained relatively flat — and far too high-for the past decade or so. The National Safety Council estimates that for the past 10 years, drunk driving crashes (BAC $>80 \mathrm{mg} / \mathrm{dL}$ ) have continued to be responsible for approximately $30 \%$ of all crash fatalities in the US [2], which equates to approximately 10,000 deaths every year [2]. Thus, although significant inroads have been made in reducing drunk driving crashes and fatalities, drunk driving continues to claim the lives of far too many on our roadways.

The COVID-19 pandemic has had significant consequences on alcohol and drug use. Alcohol sales increased as people were required to become more homebound [15], and now studies are showing increases in both the amount of alcohol consumed and in the number of days under the influence during lockdown phase of the pandemic [16]. With more and more states' lifting of COVID restrictions on group gatherings on the horizon, an increase in group gatherings and travel-with a resulting increase in driving after drinking-is highly likely.

Currently, the blood alcohol concentration (BAC) cut-off level for drunk driving is set at $80 \mathrm{mg} / \mathrm{dL}$ for most states in the USA. Research from many sources has shown that driving performance is impaired at even lower concentrations (see [17] for review). Several countries [18] and the State of Utah [19] in the US have adopted a lower drunk driving BAC cut-off at $50 \mathrm{mg} / \mathrm{dL}$, and several other states-including Hawaii, Virginia, New York and Michigan-have considered and debated legislation to reduce their BAC cut-off to $50 \mathrm{mg} / \mathrm{dL}$ [17]. Many groups such as the World Health Organization and the National Transportation Safety Board have supported this move [20]. It has been estimated that lowering the drunk driving BAC cut-off to $50 \mathrm{mg} / \mathrm{dL}$ would save on average 500-800 lives every year in the US alone [20,21].

BAC cut-offs for drunk driving differ across countries throughout the world [18]. In many countries in Africa and South America, in most of the countries of the European Union (EU) and in Australia, the BAC cut-off for drunk driving is $50 \mathrm{mg} / \mathrm{dL}$. Indeed, the $80 \mathrm{~g} / \mathrm{dL}$ BAC cut-off for drunk driving is used in only a handful of countries, including the US. Reducing the BAC cut-off has reduced crashes and saved lives lost to drunk drivers. For example, in 1998, Austria decreased the BAC cut-off to $50 \mathrm{mg} / \mathrm{dL}$; this change decreased drunk driving accidents by nearly 10\% [22]. According to the National Transportation Safety Board [20], in 2015, 31\% of the crash deaths in the United States involved alcohol. By contrast, in the Netherlands, where the BAC cut-off is $50 \mathrm{mg} / \mathrm{dL}$, only $19 \%$ of traffic related deaths involved alcohol. The NTSB concluded "...twenty years of international studies have shown that when a country lowers BAC limits from $80 \mathrm{mg} / \mathrm{dL}$ to $50 \mathrm{mg} / \mathrm{dL}$, alcohol-related fatal and injury crashes decrease between 5\% and 10\%." [20].

The statistics regarding the effects of alcohol on driving performance often have focused on fatal crashes, with less emphasis on severe or non-severe non-fatal crashes. Perhaps this reflects the impact of limited resources available for investigation, i.e., greater investigative resources for fatal crash investigations. For whatever reason, it remains the case that the quality of the databases is oftentimes less robust for non-fatal crashes (see, for example [23]). Focusing on high-profile fatal crashes may result in the skewing of the 
data toward higher BAC levels, and thus understate the adverse consequences of more moderate alcohol intoxication.

Several studies have reported adverse effects of ethanol on road driving [24,25], as well as simulator performance [26-28]. These studies have used many measures, but one of the most commonly used measures of drunk driving is the Standard Deviation of Lane Position (SDLP), essentially a measure of weaving while driving. Recently, our laboratory has used a driving simulator to study crash avoidance reaction time, a measure related to defensive driving ability. We have shown that both low dose alcohol (BAC: 50-80 mg/dL) and marijuana ( $10 \mathrm{mg}$ edible THC, blood concentration $<3 \mathrm{ng} / \mathrm{mL}$ ) cause an increase in crash avoidance reaction time in this defensive driving task [29].

Driving simulators have also been used as educational tools regarding the hazards of distracted and impaired driving. For example, the APlusB simulator company has advocated for using portable simulators with a drunk driving program to provide educational experiences regarding the effects of alcohol on simulator driving performance (APlusB Inc., Richmond, OH, USA, 2021) In addition, Innocorp has developed a hands on educational tool using go-carts and 'beer goggles' to help young drivers appreciate the hazards of drunk and impaired driving [30].

In addition to our academic studies on the effects of distractions (texting [31,32], and drug effects [29] on driving performance and driving safety, our research group also has been involved in public safety presentations to the community regarding the dangers of distracted driving and impaired driving. In the impaired driving presentations we have used a fixed-base driving simulator located in our college, with a 'demonstration subject' consuming real alcohol to achieve a measured BAC 50-75 mg/dL (not legally drunk in Michigan) and then demonstrating an impairment in crash avoidance driving performance. These hands-on demonstrations are an engaging and useful educational tool, but with a fixed base simulator (full size car in a laboratory room) they are limited to in-house presentations.

Recently, our research group started working with a portable driving simulator [17], using virtual reality (VR) technology and specific software provided by Mahmoud Mattan at Brand XR (Orlando, FL). Before the COVID-19 outbreak, it was our plan to take this portable system "on the road"-figuratively speaking-for hands-on community informational presentations about the hazards of buzzed and/or drunk driving. Imagine, for example, a community leader in your town - the Mayor or the Chief of Police-'driving' (in an auditorium in a 'town hall' setting) a VR-based simulator (described below in detail) and providing a first-hand demonstration of how even low doses of alcohol can adversely affect your driving ability. (Of course, they would have a designated driver for the trip home afterward). Since we cannot take our presentation to the community during the pandemic, we are sharing it at this time with the readers of Substance Abuse Treatment, Prevention, and Policy. The testing procedure is fun and easy to learn and, as we shall demonstrate, is highly sensitive to the disruptive effects of ethanol on driving performance. Thus, the present paper describes a hands-on public awareness outreach program for demonstrating the hazards of (real) drunk driving, and the relationship between BAC levels and driving performance. The present paper also demonstrates very clearly the impairing effects of ethanol on driving even when the BAC is less than $80 \mathrm{mg} / \mathrm{dL}$, i.e., the legal cut-off for drunk driving in most states in the US.

\section{Materials and Methods}

Subject. Rather than the Mayor or the Chief of Police from the local municipality, the subject for this study is Dr. Commissaris, the project's Principal Investigator. At the time of the study, he weighed 205 pounds and had a body mass index (BMI) of 26. The subject has a history of occasional drinking, i.e., up to two alcoholic drinks/day socially as frequently as 2-3 times per week for the past six months. Except for his participation in the present study, he has not consumed more than 4-5 drinks in a single setting in over 20 years. The studies were conducted in accordance with Wayne State University IRB 
\#066716B3E. Normally, i.e., in non-COVID times, i.e., with the current IRB, subjects would be male and female, across a range of ages. In addition, the subjects would be characterized via survey as occasional, moderate or relatively heavy alcohol users. This would allow for an analysis of the potential influence of alcohol tolerance.

Apparatus. Figure 1 below depicts the subject and the test apparatus used in the present.

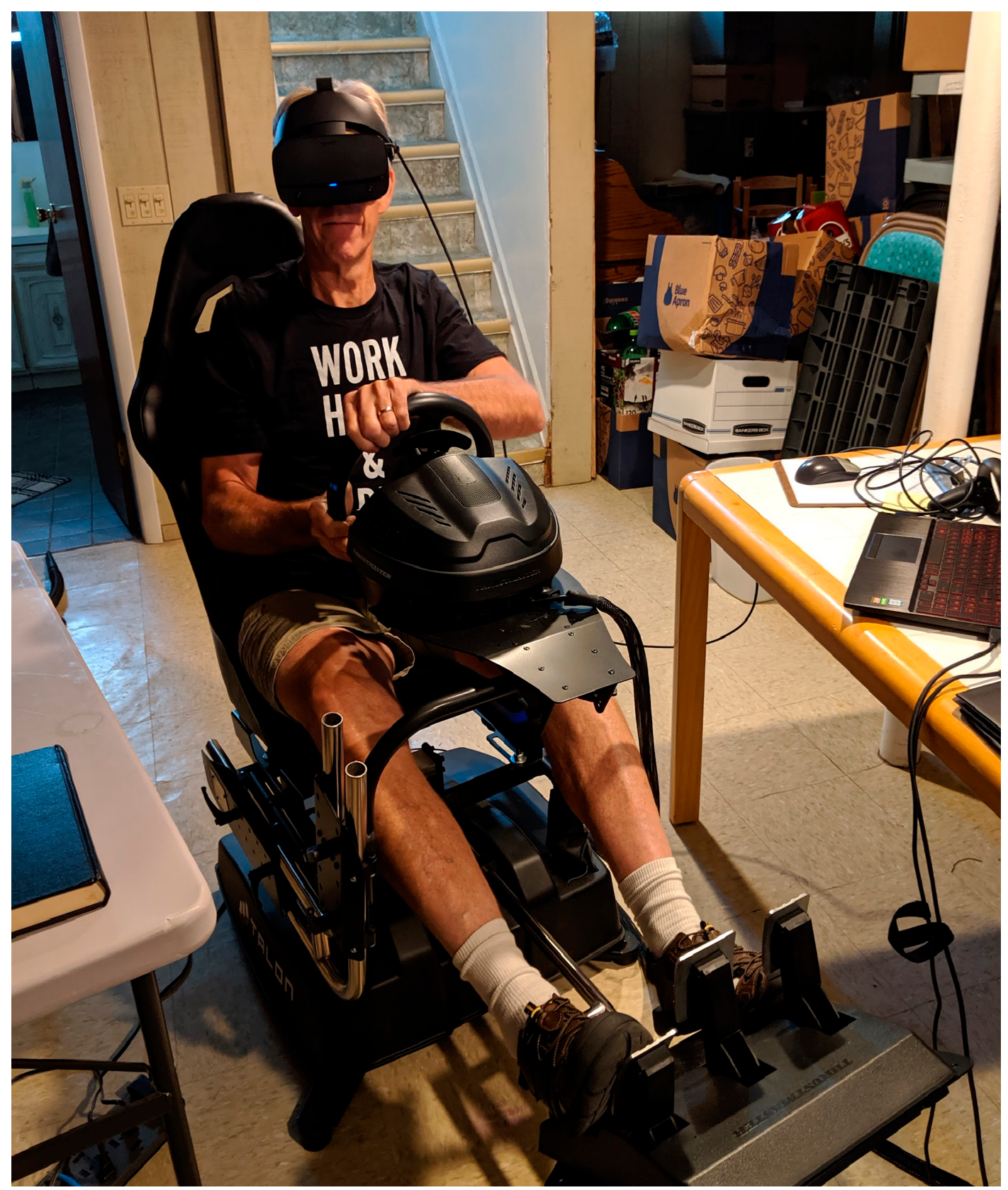

Figure 1. The subject and the testing apparatus.

Study. The gaming chair was purchased from Talon Corporation (Los Angeles, CA, USA) and the model was the Atomic A3 Motion Simulator using the racing/flight system. The VR headset was a standard commercial Oculus Rift-S headset. The specific crash avoidance computer program is a proprietary product created for Wayne State University by Brand XR (Orlando, FL, USA). The open source platform Steam was used to communicate between the software and the VR headset and the gaming chair. 
Crash avoidance reaction time was the primary measure of driving performance. In this VR-based game-like procedure, the driver is instructed to drive at $70 \mathrm{mph}$ ('pedal to the metal'; a programming governor limits the top speed at $70 \mathrm{mph}$ ) and stay in the middle lane of a three-lane road. At randomly occurring times during the drive, a 'stalled car' instantly appears in the road ahead. The stalled car is too close ( $40 \mathrm{~m}$ headway distance) to avoid a crash via braking; the only way to avoid crashing into the stalled car is to rapidly steer around the car. The steering response should be hard to the left or hard to the right, and is determined by the location of the stalled car, i.e., slightly right of center or slightly left of center; the relative position of the stalled car is unknown to the driver. Thus, this is a type of 'choice' reaction time measure.

The timing during the drive for the appearance of the stalled car and the crash avoidance trials was random and different for every drive. The average interval between crash avoidance trials was $25 \mathrm{~s}$, but some individual trials occurred at an interval as short as $10 \mathrm{~s}$ and others as long as $45 \mathrm{~s}$ after the previous trial. The subject knew that a crash avoidance trial would occur, but the subject did not know precisely when the crash avoidance situation would be presented.

Figure 2 presents a cartoon depicting the nature of this choice reaction driving task.

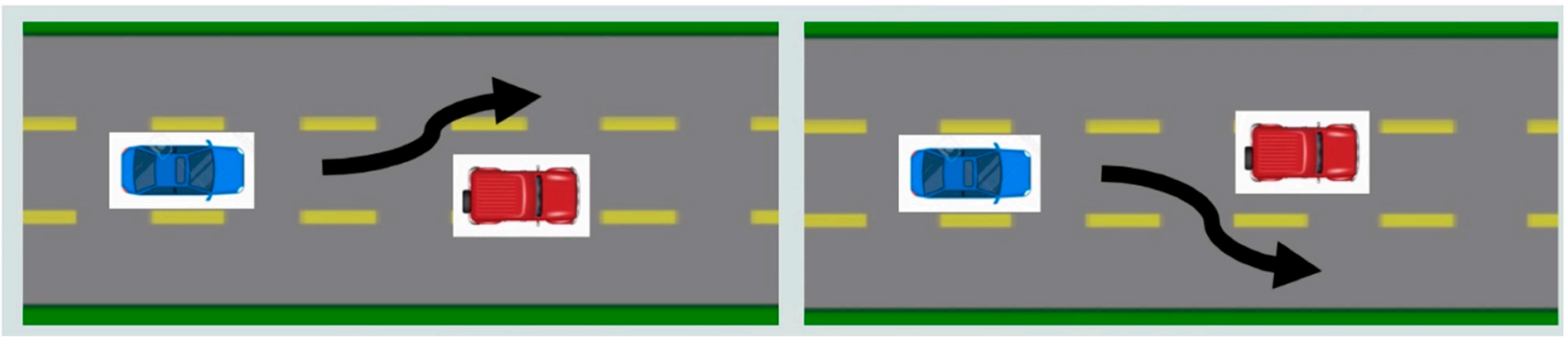

Figure 2. Illustration of the 'go left' and 'go right' trials utilized in the crash avoidance steering reaction paradigm. The driver (blue car) is traveling at $70 \mathrm{mph}$ in the center lane and the 'stalled car' (red car) appears $40 \mathrm{~m}$ ahead. The driver has to 'read' the situation and make a quick and sharp left or right turn to avoid a crash.

In the present study, initiation of an avoidance steering response was defined as the moment that the steering wheel reading reached 5 degrees or greater. This cut-off was selected somewhat arbitrarily, and reflects a balance between serious aggressive crash avoidance turning and the more slight moment-to-moment minor steering corrections that a driver engages in while driving in the center lane at $70 \mathrm{mph}$. Pilot studies revealed that simply "wiggling" the steering wheel a little bit while remaining in the center lane generates steering responses of $<1-2$ degrees, i.e., well below the 5 degree cut-off. As you can see in Figure 3 of the manuscript, 5 degrees of turning in this task corresponds to about $30 \%$ of the maximal turning accomplished; thus, this steering response is clearly an aggressive crash avoidance steering response and not the ordinary 'wiggle' that one engages in simply in order to remain in the middle lane.

The primary measure of driving ability is the reaction time (in ms) to initiate an avoidance steering response, i.e., steering $\geq 5$ degrees. Dr Commissaris is an experienced driver in this task, and he typically performs this crash avoidance response reliably (correct avoidances $>99 \%$ of all trials), with an average reaction time between 305 and $315 \mathrm{~ms}$. 


\section{Crash Avoidance Steering Response}

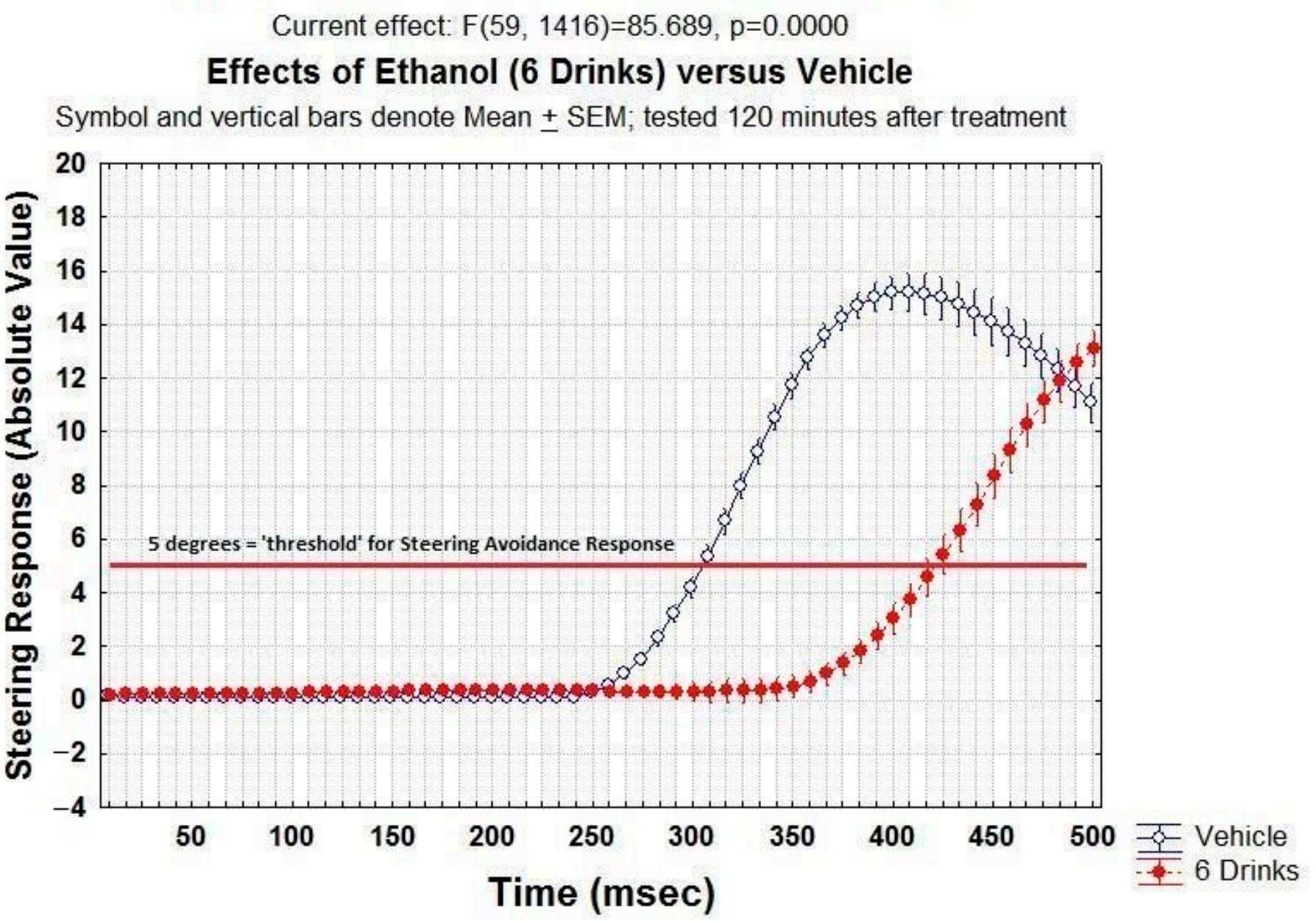

Figure 3. Time course for the crash avoidance steering response following either vehicle or 6 drinks ( 9 ounces of 80 proof vodka). Plotted are the mean \pm SEM values for steering wheel activity over the course of the first $500 \mathrm{~ms}$ following presentation of the stalled car. The absolute value of steering was used to normalize for right (positive values) and left (negative values). As can be seen, following vehicle treatment, no response is apparent until at least $250 \mathrm{~ms}$ and the threshold for steering response (defined as turning $\geq 5$ degrees) was reached at approximately $310 \mathrm{~ms}$. These values were significantly and dramatically increased following high-dose alcohol treatment (see text for details).

Procedure. On multiple occasions during a three-month period, with each occasion separated by approximately 3-5 days, the laboratory group (via ZOOM meetings) conducted a study on the effects of alcohol or placebo (no drug) on crash avoidance reaction time using the VR-based driving simulator. All treatments (vehicle, 2 drinks, 4 drinks or 6 drinks) were 'replicated' on 4 occasions over the course of three months. On each of the treatment days, the subject was tested in a pre-treatment drive, with subsequent drives conducted every $30 \mathrm{~min}$ after treatment for a period of $4-6 \mathrm{~h}$, depending on the treatment. For the alcohol treatment days, drives were immediately preceded by estimations of BAC using the BAC track S80 personal use breathalyzer device (KHN Solutions, San Francisco, CA). Two BAC track devices were used; the BAC value recorded at each pre-drive timepoint was the average of the two meter readings. The duration of the drive test is 5-7 min, so the pre-drive BAC determinations were closely connected with driving performance at that time.

The repetitive nature of the task is not problematic. It is correct that subjects exhibit something of a learning curve, i.e., reduced reaction times over the course of the first $3-5$ trials in the first driving test, i.e., when first introduced to this task. This learning curve 
occurs rapidly and stabilizes within the first few trials. After this initial accommodation to the task, crash avoidance reaction times are remarkably stable across multiple subsequent test sessions. This is evidenced by the similarity in the reaction times for the pre-treatment (control) drives both within and across multiple test sessions.

Dependent Variables and Statistical Analyses. The dependent variables measured were: (1) the crash avoidance reaction time, defined as the time in ms from the appearance of the stalled car until the steering wheel was turned $\geq 5$ degrees and (2) BAC, measured using the BAC Track devices. For the analysis of the time-course for the effects of different treatments on crash avoidance Reaction time, the data were analyzed using a 4 (Doses: Veh, 2, 4, 6 Drinks) $\times 7$ (Time: Pre-Tx, 30, 60, 90, 120, 150, $180 \mathrm{~min}$ ) Factorial ANOVA, with the time as a repeated measure. In the analysis of the time-course for alcohol concentrations versus treatments, the data were analyzed using 4 (Doses: Veh, 2, 4, 6 Drinks) $\times 6$ (Time: $30,60,90,120,150,180 \mathrm{~min})$ factorial ANOVA, with the time as a repeated measure. Reaction times for various BAC concentration groups were analyzed using a One-way ANOVA with four levels $(0.0 \mathrm{mg} / \mathrm{dL}\{$ Pre-Tx $\}, 10-49.9 \mathrm{mg} / \mathrm{dL}, 50-79.9 \mathrm{mg} / \mathrm{dL}, \geq 80 \mathrm{mg} / \mathrm{dL})$ irrespective of dose administered. In all comparisons, $p<0.05$ was the criterion for statistical significance.

\section{Results}

Figure 3 below illustrates the typical raw data generated for this crash avoidance steering response two hours after treatment with a relatively high dose of ethanol (6 drinks $=9$ ounces of 80 proof vodka; red line) or vehicle (blue line). This figure depicts the steering wheel response (absolute value) as a function of time after the appearance of the stalled car. Steering wheel activity is sampled 120 times/sec with this device, so each point along the $x$-axis represents steering wheel activity ( $y$-axis) during the first $500 \mathrm{~ms}$ following the appearance of the stalled car, separated into approximately $8.3 \mathrm{~ms}$ epochs. As can be seen, even when sober (vehicle curve) there is a significant delay for the initiation of a steering avoidance response. Using the criterion of 5 degrees steering as the operationally defined initiation of a significant avoidance response, the time for initiation of a significant steering response was approximately $310 \mathrm{~ms}$ after vehicle treatment, but increased dramatically to over 430 ms-two hours after the subject had consumed six alcoholic drinks (red trace). Statistically, there was a significant main effect for ethanol treatment $(\mathrm{F}(1,24)=131.62$, $p<0.05)$ and for Time $(8.33 \mathrm{~ms}$ steering epochs $)(\mathrm{F}(59,1416)=311.84, p<0.05)$; the ethanol treatment-time interaction also was significant $(\mathrm{F}(5,1416)=85.69, p<0.05)$.

Figure 4 below illustrates the time course for the effects of different doses alcohol. In this graph, the $y$-axis is the mean crash avoidance reaction time in ms, i.e., the time to initiation of a 5 degree steering response; the $x$-axis is the time (in 30 min epochs) after treatment with vehicle, two, four or six drinks. As can be seen, vehicle treatment had no effect on crash avoidance reaction time. Alcohol significantly increased crash avoidance reaction time in both a dose-dependent and time-dependent manner. Statistically, there was a significant main effect for ethanol dose $(\mathrm{F}(3,10)=56.61, p<0.05)$ and a significant main effect for time $(\mathrm{F}(6,60)=16.49, p<0.05)$; and a significant ethanol dose-time interaction $(\mathrm{F}(18,60)=6.97, p<0.05)$. Post hoc Student-Newman-Keuls (SNK) tests revealed significant increases in reaction time (compared to vehicle treatment) following four drinks or six drinks at several times post-treatment.

Figure 5 depicts the dose-response plot for the effects of ethanol on crash avoidance reaction time for the period 30-180 min post administration. As can be seen, ethanol produced a dose-dependent increase in crash avoidance reaction time. Statistically, there was a significant effect of Ethanol dose $(\mathrm{F}(3,10)=64.60, p<0.05)$; post hoc SNK comparisons revealed that both four drinks ( 6 ounces of vodka) and six drinks significantly increased crash avoidance reaction time when compared to vehicle-treated controls over the same period. 


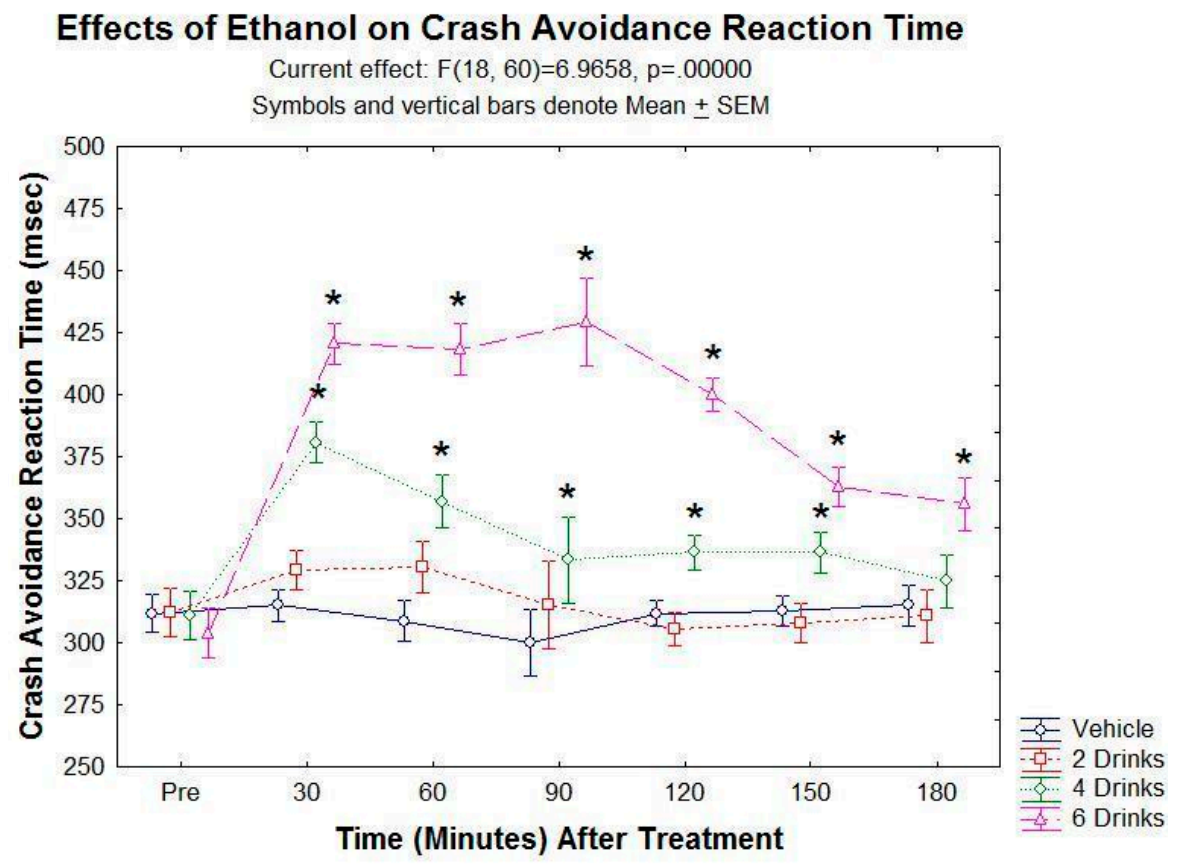

Figure 4. Time course for the effects of alcohol on crash avoidance reaction time. Plotted are the mean \pm SEM values for crash avoidance reaction time before (Pre) and at 30, 60, 90, 120, 150 and 180 min following treatment with 0 (Vehicle), 2, 4 or 6 drinks of alcohol (see text for further details). *-reaction time at the indicated test time is significantly different from Pre-Tx value for that treatment, Student-Neuman-Keuls (SNK) test following factorial ANOVA.

\section{Ethanol Effects on Crash Avoidance Reaction Time \\ Current effect: $F(3,10)=64.660, p=.00000$ \\ Data Pooled Across 30-180 Minute Tests \\ Vertical bars denote \pm SEM}

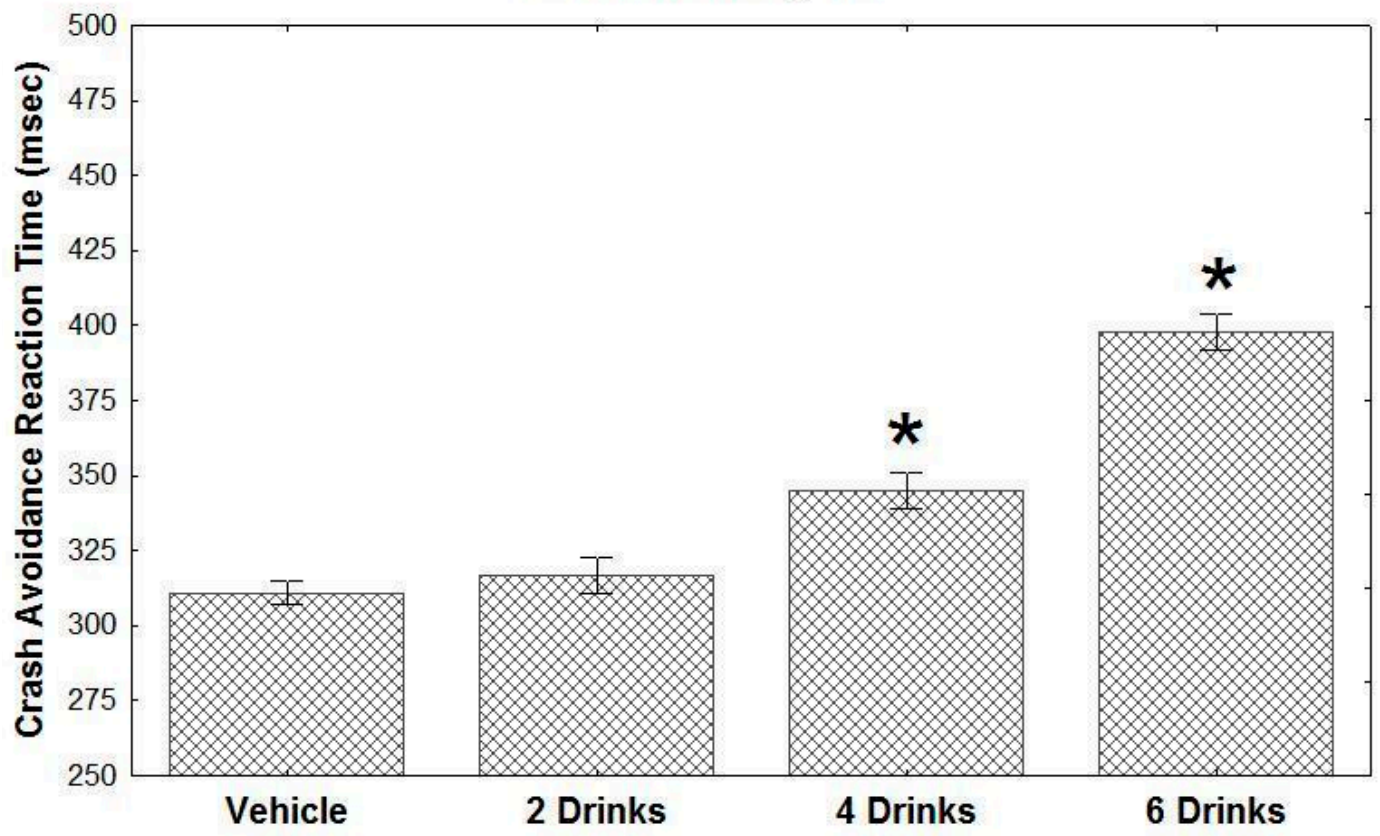

Figure 5. Dose-response for the effects of alcohol on crash avoidance reaction time, 30-180 min following treatment. Plotted are the mean \pm SEM values (pooled across the period 30-180 min post-treatment) for crash avoidance reaction time following treatment with 0 (Vehicle), 2, 4 or 6 drinks of alcohol (see text for further details). * -reaction time for the indicated treatment is significantly different from vehicle controls, Student-Neuman-Keuls (SNK) test following factorial ANOVA. 
BAC concentration measurements using the two BAC Track devices were in strong agreement, with a correlation of $r=0.98$ across the multiple BAC determinations (data not shown). Figure 6 below depicts the ethanol concentrations for the $3 \mathrm{~h}$ post-treatment period for the three ethanol doses. As can be seen, the peak ethanol concentration varied significantly with ethanol dose, but the fall in the concentration over time was similar across the three doses, consistent with the primarily zero order metabolism of ethanol (Pawan, 1972). Statistically, there was a significant main effect for ethanol dose $(\mathrm{F}(2,6)=308.83$, $p<0.05)$ and for time $(\mathrm{F}(5,30)=43.58, p<0.05)$; the ethanol dose-time interaction was also significant $(\mathrm{F}(10,30)=2.32, p<0.05)$.

\section{Blood Alcohol Concentration (BAC) Versus Time \\ Current effect: $F(10,30)=2.3221, p=.03645$ \\ $\mathrm{BAC}$ measured via breathalyzer \\ Symbols and vertical bars denote Mean \pm SEM}

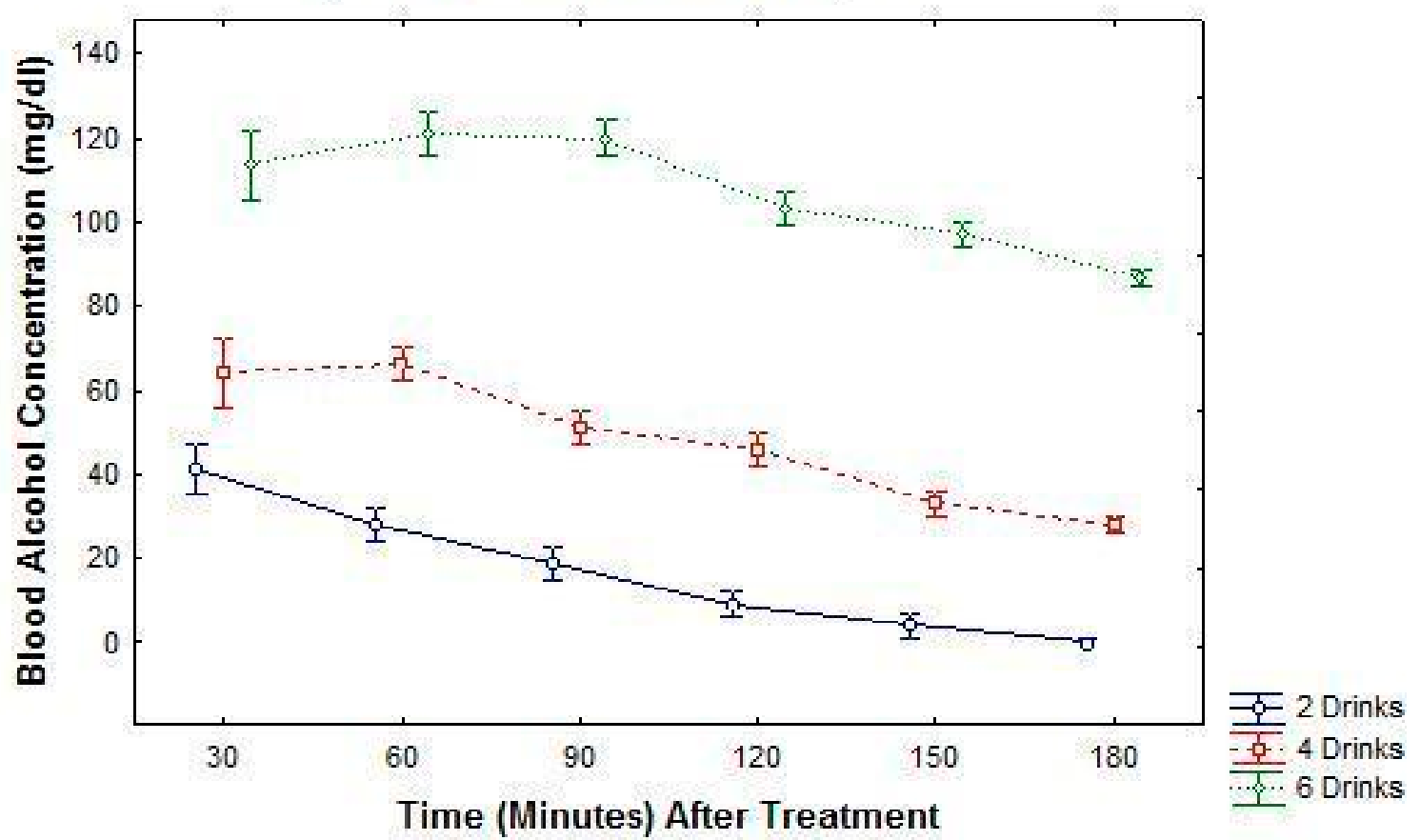

Figure 6. Ethanol concentration versus time curves for 2, 4 and 6 drinks. Plotted are the mean \pm SEM values (mg/dL) for ethanol at 30, 60, 90, 120, 150 and 180 min following administration of 2, 4 or 6 drinks (see text for further details).

Figure 7 below is a scatterplot depicting the relationship between BAC $(>10 \mathrm{mg} / \mathrm{dL}$; the threshold for detection with the BAC Trak devices) and driving performance across multiple driving tests at various times following the alcohol treatments. As can be seen, there is a highly significant correlation $(r=0.854 ; p<0.05)$ between BAC and crash avoidance reaction time across the full range of BAC levels. 


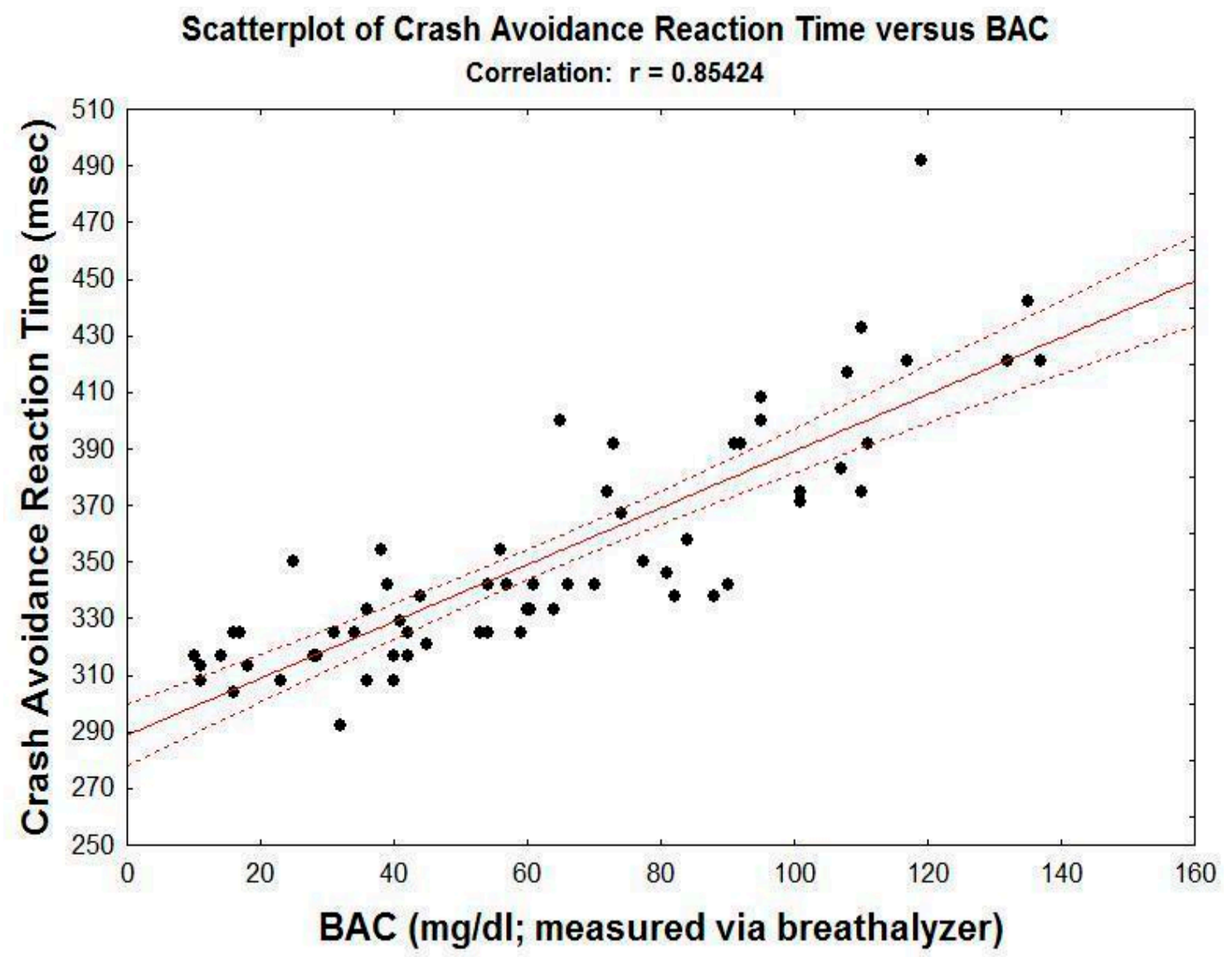

Figure 7. Scatterplot of crash avoidance reaction time versus BAC. Plotted are the individual values for crash avoidance reaction time across all test sessions and the correlated BAC values for those crash avoidance tests. BAC values of $<10 \mathrm{mg} / \mathrm{dL}$ were excluded because they register at $0 \mathrm{mg} / \mathrm{dL}$ on the meter. The Pearson correlation coefficient $(\mathrm{r}=0.85)$ was statistically significant (see text for further details).

Finally, Figure 8 below illustrates crash avoidance reaction time when the data are grouped into various BAC categories: (1) $0.0 \mathrm{mg} / \mathrm{dL}$, i.e., from Pre-Tx drives, (2) $>10$ but less than $50 \mathrm{mg} / \mathrm{dL},(3) \geq 50 \mathrm{mg} / \mathrm{dL}$ but $<80 \mathrm{mg} / \mathrm{dL}$ and (4) $\geq 80 \mathrm{mg} / \mathrm{dL}$. As can be seen, concentrations of $50-80 \mathrm{mg} / \mathrm{dL}$ significantly increased crash avoidance reaction time. Statistically, there was a significant effect for BAC category $(\mathrm{F}(3,75)=40.75, p<0.05)$; post hoc SNK tests revealed a significant difference between Pre-Tx performance and both the $\mathrm{BAC}=50-79.9 \mathrm{mg} / \mathrm{dL}$ group and the $\mathrm{BAC} \geq 80 \mathrm{mg} / \mathrm{dL}$ condition. 


\section{Crash Avoidance Reaction Time versus BAC 'Category' \\ Current effect: $F(3,75)=40.745, p=.00000$ \\ Vertical bars denote \pm SEM}

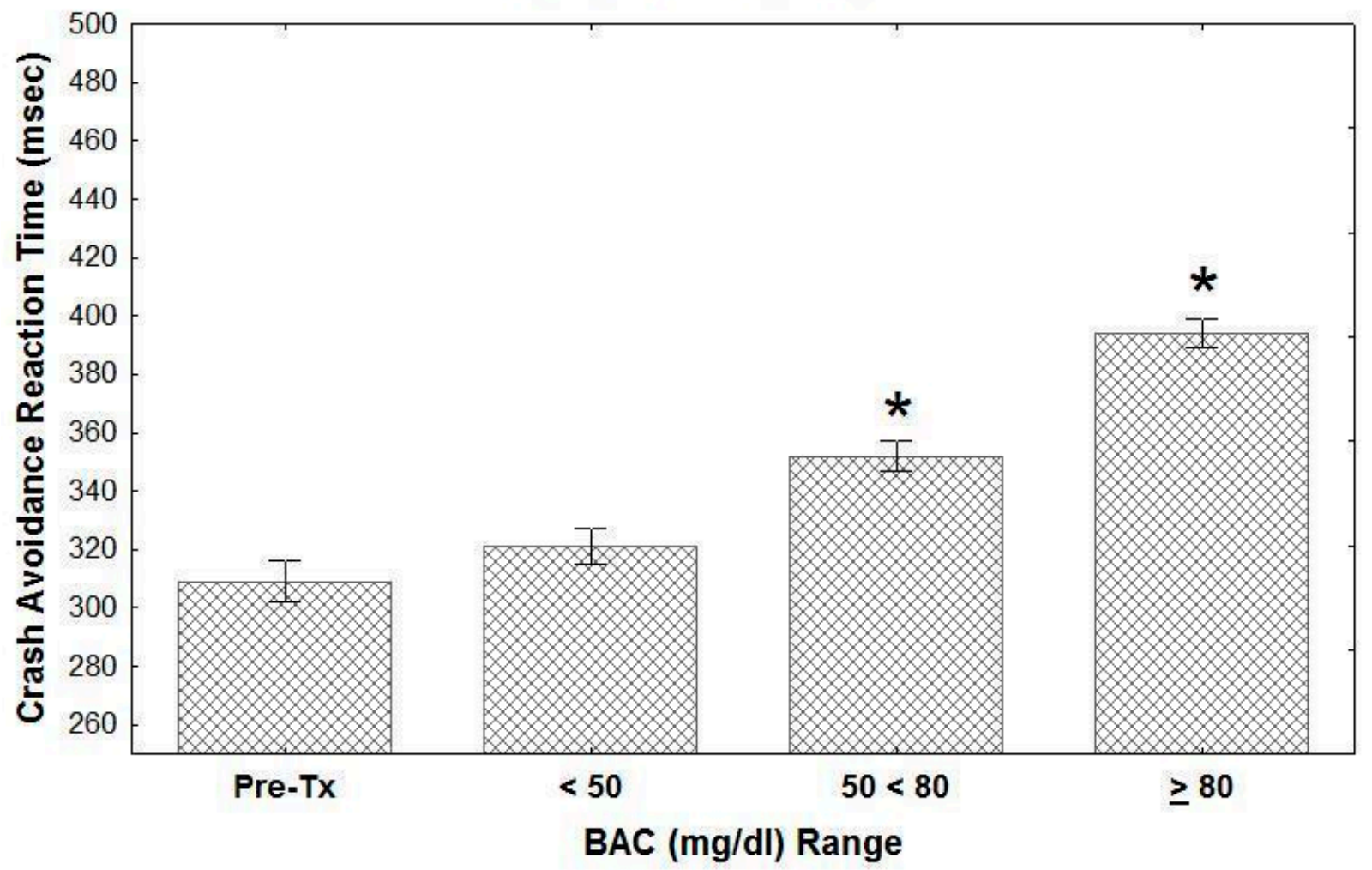

Figure 8. Crash avoidance reaction times for different BAC ranges. Plotted are the Mean \pm SEM values for crash avoidance reaction as a function of the BAC Range; BAC was determined immediately prior to the crash avoidance test. *-Statistically different from Pre-Treatment control values (BAC $=0 \mathrm{mg} / \mathrm{dL}$ ), SNK test following one-way ANOVA.

\section{Discussion}

The problem of drunk driving has existed as a significant issue in society ever since the first automobile was built. Over the past 40 years, there have been significant improvements in vehicle crash safety features (air bags, anti-lock brakes, lane-keeping functions, etc.), and there have been public service campaigns to increase awareness of the problem. As discussed by Madden and McCambridge [14], over the same time span alcohol marketing messaging often has run counter to the road safety messaging. Given the significantly greater resources of the latter, this creates a 'David and Goliath' situation, resulting in the situation where drunk drivers continue to take a significant number of lives on our roadways [14]. The present paper argues that this sad statistic may relate in part to the lack of full appreciation of the adverse effects of moderate intoxication on driving ability and performance. This paper then describes a method for delivering a "Don't drink and drive" message that is hands-on, fun and engaging, but perhaps most important, clearly demonstrates the significant adverse effects of even moderate alcohol intoxication.

The present paper describes the effects of alcohol on driving performance using a portable VR-based driving simulator choice reaction task for assessing defensive driving skills. The procedure is fun and easy to learn, and crash avoidance reaction times are robust and reliable using only a single demonstration subject. As expected, crash avoidance reaction time was increased by alcohol treatment in a dose- and time-dependent manner. Breath-based BAC determinations conducted immediately before testing revealed a strong correlation between BAC and crash avoidance reaction time. Finally, analysis of the crash avoidance reaction time based on the range of pre-drive $B A C$ values revealed a significant increase in crash avoidance when BAC values ranged between 50 and $79.9 \mathrm{mg} / \mathrm{dL}$, with 
an even greater increase in crash avoidance time when BAC values were $\geq 80 \mathrm{mg} / \mathrm{dL}$, i.e., what is currently considered 'alcohol intoxicated' in most US states.

Increased reaction time is a potential cause for alcohol-related crashes, and several studies have reported that alcohol increases reaction time ([33-36]. These studies have included tests where the reaction time task was a secondary task in the driving setting. The present study uses a two-choice reaction defensive driving task in which the avoidance reaction task is a central component of the safe driving situation. In the present study, the reaction time on control/sober drives (i.e., Pre-Treatment or following vehicle treatment) was approximately 300-315 ms. The actual initiation of the steering response is closer to $260 \mathrm{~ms}$ (see Figure 3), a reaction time that is comparable to the average 'mouse click' reaction time achieved by this subject $(255-275 \mathrm{~ms})$ in an online reaction time assessment test (https: / / faculty.washington.edu/chudler/java/redgreen.html; accessed on 5 August 2021). Finally, it should be noted that in the present study, driving speed was held constant at $65 \mathrm{mph}$. This creates an opportunity to separate the potentially confounding effects of alcohol on driving speed (alcohol typically increases driving speed significantly) from the effects of alcohol on reaction time.

The present results support the argument that BAC values of $50<80 \mathrm{mg} / \mathrm{dL}$ should be included as part of the legal cut-off for drunk driving. This argument has been argued by several driving safety organizations (see Zohr et al [7]) and has been supported by the results of previous open road [24,25] as well as simulator studies [26-28]. The present study is the first to demonstrate the adverse effects of these relatively low alcohol concentrations using a simulator-based defensive driving choice reaction task. Given that reaction time is critical for avoiding a crash in many defensive driving situations, the present results would translate to an impaired ability to engage effectively in defensive driving maneuvers, and thus would increase the likelihood of a crash at BAC values $50-80 \mathrm{mg} / \mathrm{dL}$ alcohol. These findings are consistent with studies that have demonstrated reduced alcohol-related crashes after the legal BAC cut-off for impaired driving was reduced to $50 \mathrm{mg} / \mathrm{dL}$ [20]. As has been argued previously [17], from a policy and legal perspective, it also makes sense for the penalty for driving with a BAC 50-79.9 to be less severe than the penalty for driving with a $\mathrm{BAC} \geq 80 \mathrm{mg} / \mathrm{dL}$.

The second conclusion is more of a prediction, which is that public, hands on demonstrations using this VR-based driving simulator procedure-or something similar-could be a powerful, cool and user-friendly tool to use in combating the problem of drunk and buzzed driving, especially among younger drivers. A somewhat similar approach utilizing go-cart driving and 'beer goggles' has been promoted by the Innocorp Corporation as a way to increase appreciation of the dangers of drunk driving [37]. Similarly, we have used beer goggles in both research projects [31] and in public service presentations ("Don't text and drive in the motor city") to demonstrate how visual disturbances can exacerbate distracted driving problems (i.e., texting while driving). Although useful, these beer goggle approaches focus only on the visual problems produced by alcohol (and other drugs) and yet, as demonstrated in the present study, other effects of alcohol, such as those on reaction time, are also critically important for safe driving.

This VR driving experience is fairly modest in terms of the VR effects, i.e., it does not simulate your whole body moving through space as in, for example, when someone is interacting with others via the Internet in a multi-party virtual game situation. As such, the need for VR adaptation by the subject is minimal. Indeed, VR-naive subjects adapt rapidly to the VR aspect of this task. It is also the case that, in contrast to many more interactive game situations, participating in this VR game produces little or no VR sickness. We are currently pursuing an answer to that question now that the COVID-19 pandemic is settling down. Initial studies suggest that control driving is comparable for the VR headset when compared to driving while watching on a flat screen instead of watching via the VR headset. However, of course, the VR experience is a bit 'cooler'.

In terms of implementing law and policy changes, sometimes seeing is believing, which makes this the first step. As recalled by retired Los Angeles Police Department 
(LAPD) officer Thomas Page, the value of a 'hands on' approach to understanding the effects of alcohol was demonstrated in the 1980s when officers from the LAPD met with a cohort of judges and prosecuting attorneys in LA County and got them intoxicated to a BAC level of $80 \mathrm{mg} / \mathrm{dL}$, at a time when the BAC cut-off for drunk driving was then still $100 \mathrm{mg} / \mathrm{dL}$. Experiencing the effects of $80 \mathrm{mg} / \mathrm{dL}$ for themselves, and seeing their colleagues experiencing the effects of $80 \mathrm{mg} / \mathrm{dL}$, was strong evidence, and led to significantly increased support for implementation of the BAC $80 \mathrm{mg} / \mathrm{dL}$ cut-off [38]. In a similar manner, a greater appreciation of the dangers of drunk driving, even when the BAC is less than the current legal cut-off for intoxicated driving $(80 \mathrm{mg} / \mathrm{dL}$ in Michigan, for example), might come from hands on experience with the effects of alcohol using a driving simulator. We have beta-tested this 'hands on' approach in internet ZOOM presentations as part of a university class, and also for an advocacy group (Michael Tobias and the Michigan Coalition to Reduce Underage Drinking; mcrud.org) and a State of Michigan legislator (Legislative Director Megan Kiefer from the Office of State Legislator Abdullah Hammoud, Dearborn). We plan to take this portable VR-based driving simulator 'on the road' and bring "Move the BAC cut-off for drunk driving to $50 \mathrm{mg} / \mathrm{dL}$ " messaging [17] to community groups as soon as possible after the current COVID-19 situation. This public outreach approach has been highlighted recently in a feature article in the Detroit News by Neil Rubin [39].

It is also the case that a driver's self-perception of the level of her/his intoxication is an important factor that sometimes results in a 'buzzed' driver getting behind the wheel and driving [40], i.e., "I'm a little tipsy, yeah, but I think I'm still OK to drive". That perhaps is one of the more important aspects of the approach described in the present paper, since the driver/subject may feel pretty good, i.e., 'unaffected', after only a few drinks, but when driving performance is directly assessed, it becomes clear to the subject that her/his 'buzzed driving' is indeed drunk driving.

The approach and results described in the present studies could be used to complement many of the strategies that are currently used to reduce drunk driving today [21,41,42]. Use of BAC-based ignition lockout devices has been permitted in all 50 states since 2012, and has been proposed as part of the federal government infrastructure bill ([43]; see also [6]. In addition, designated driver campaigns have been in existence for several years and have been shown to reduce alcohol use by, and subsequent intoxication of, the designated driver [44]. Hafner and colleagues showed that viewing mock alcohol-related car crashes, combined with authoritative and accurate information regarding the adverse effects of alcohol on driving, significantly reduced the likelihood to drink and drive [45]. It is anticipated that a hands-on and user-friendly, "Don't drink and drive" campaign involving real alcohol intoxication in a driving scenario will further reduce driving while intoxicated.

The present study has several limitations. Perhaps first and foremost is the fact that only one subject was studied, and the study was conducted in an open label manner. It is correct that the data are from only one subject. This was because of the 'lock-down' associated with the COVID-19 outbreak. However, two things should be noted. First, this subject was tested on multiple occasions and under identical conditions with each of the various treatment conditions. Second, pilot studies in other subjects, although far less extensive in their scope, have also revealed similar control response times and impaired crash avoidance reaction times with BAC levels $50-80 \mathrm{mg} / \mathrm{dL}$. Future studies to replicate and expand upon these findings are needed; these studies are indeed planned.

Another limitation is that the present study analyzed only one component of driving safety, i.e., the latency for a steering avoidance response to a potential crash situation. Although the debilitating effects of alcohol on this measure are clear and dramatic even at low ethanol concentrations, the effects of alcohol on other measures of driving safety, e.g., driving speed, braking time, decision-making, should be evaluated in future studies. Nonetheless, these studies demonstrate a significant impairment of defensive driving behavior at relatively low BAC levels. 


\section{Conclusions}

In summary, this VR-based simulator task has a 'gaming' quality that makes it fun for many users-and even non-users - of VR-based gaming, but it also clearly demonstrates, with safety-relevant 'hard data' regarding crash avoidance reaction times, that even a few drinks can have significant adverse effects on driving performance and driving safety. Thus, the final take-home message is pretty clear: do not drink and drive, because even alcohol concentrations below the current drunk driving cut-off can significantly impair your driving performance.

Author Contributions: J.A. initiated the studies and wrote the first draft of the manuscript. J.A., Z.S., M.M., E.N., T.M.-z., T.H., T.Z., D.H. and R.C. participated in collecting the data and editing the manuscript. R.C., J.A., Z.S., M.M. and T.Z. conducted the statistical analyses of the data and generated the figures. All authors read and approved the final manuscript.

Funding: This project was supported by the Department of Pharmaceutical Sciences, the Eugene Applebaum College of Pharmacy and Health Sciences, and the Office of the Provost, Wayne State University, Detroit, MI 48202, USA.

Institutional Review Board Statement: This study was conducted according to the guidelines of the Declaration of Helsinki, and approved by the Institutional Review Board of Wayne State University (\#066716BE3).

Informed Consent Statement: Informed consent was obtained from all subjects involved in the study.

Data Availability Statement: The datasets during and analyzed during the current study are available from the corresponding author on reasonable request.

Conflicts of Interest: The authors declare no conflict of interest.

\section{Abbreviations}

ANOVA analysis of variance

BAC blood alcohol concentration

BMI body mass index

IRB institutional review board

LAPD Los Angeles Police Department

Mph miles per hour

SDLP standard deviation of lane position

SEM standard error of the mean

SNK Student-Neuman-Keuls

THC tetrahydrocannabinol

VR virtual reality

\section{References}

1. Injury Facts. Motor Vehicle Traffic Issues: Alcohol-Impaired Driving. 2020. Available online: https://injuryfacts.nsc.org/motorvehicle/motor-vehicle-safety-issues/alcohol-impaired-driving/ (accessed on 5 August 2021).

2. NHTSA. Alcohol-Impaired Driving. 2018. Available online: https://crashstats.nhtsa.dot.gov/Api/Public/ViewPublication/8126 30 (accessed on 5 August 2021).

3. Alcohol Policy Information System (APIS). The National Minimum Drinking Age Act. 1984. Available online: https:// alcoholpolicy.niaaa.nih.gov/the-1984-national-minimum-drinking-age-act (accessed on 5 August 2021).

4. Department of Transportation. 2000. Available online: https://bit.ly/37blCSA (accessed on 5 August 2021).

5. Centers for Disease Control and Prevention, National Center for Injury Prevention and Control. Breathalyzer Ignition Locks. 2016. Available online: https://www.cdc.gov/transportationsafety/impaired_driving/ignition_interlock_states.html (accessed on 5 September 2021).

6. NHTSA. Evaluation of State Ignition Interlock Programs. Interlock Use Analyses from 28 States. 2006-2011. 2015. Available online: http:/ / www.nhtsa.gov/staticfiles/nti/pdf/812145-EvalStateIgnitionInterlockProg.pdf (accessed on 5 September 2021).

7. Beck, K.H. Lessons learned from evaluating Maryland's anti-drunk driving campaign: Assessing the evidence for cognitive, behavioral, and public health impact. Health Promot. Pract. 2009, 10, 370-377. [CrossRef]

8. Centers for Disease Control and Prevention, National Center for Injury Prevention and Control. Sobriety Checkpoints. 2015. Available online: https:/ / www.cdc.gov/motorvehiclesafety/calculator/factsheet/checkpoints.html (accessed on 5 August 2021). 
9. Fell, J.C.; Lacey, J.H.; Voas, R.B. Sobriety Checkpoints: Evidence of Effectiveness Is Strong, but Use Is Limited. Traffic Inj. Prev. 2004, 5, 220-227. [CrossRef]

10. Mothers Against Drunk Driving. Available online: https://www.madd.org/the-problem/\#drunkdriving (accessed on 5 September 2021).

11. Students Against Destructive Decisions. Available online: https://dothanhighschoolsadd.weebly.com/uploads/4/7/5/2/4752 13/sadd_and_prevention (accessed on 5 September 2021).

12. Winsten, J. The Designated Driver Campaign: Why It Worked. Huffpost, 2011. Available online: https://www.huffpost.com/ entry / designated-driver-campaig_b_405249 (accessed on 5 September 2021).

13. Media Smarts. Don't Drink and Drive: Assessing the Effectiveness of Anti-Drinking Campaigns. 2011. Available online: https:/ / mediasmarts.ca/sites/default/files/lesson-plans/lesson_dont_drink_drive.pdf (accessed on 5 August 2021).

14. Madden, M.; McCambridge, J. Alcohol marketing versus public health: David and Goliath? Globilization Health 2021, 17, 45. [CrossRef] [PubMed]

15. NIAAA. Alcohol Sales during the COVID-19 Pandemic. 2021. Available online: https://pubs.niaaa.nih.gov/publications/ surveillance-covid-19/COVSALES.htm (accessed on 5 August 2021).

16. Pollard, M.S.; Tucker, J.S.; Green, H.D. Changes in adult alcohol use and consequences during the COVID-19 pandemic in the us. JAMA Netw. Open. 2020, 3, e2022942. [CrossRef] [PubMed]

17. Zohr, T.; Nwobi, E.; Masri-zada, T.; Andrews, J.; Head, T.; Awad, D.; Sareini, M.; Head, D.; Commissaris, R. Wake up America and Save Lives! Move the drunk Driving Blood Alcohol Concentration (BAC) Cut-Off to 0.05\%! J. Addict. Med. Ther. Sci. 2020. Available online: https:/ / www.peertechzpublications.com/articles/JAMTS-6-144.php (accessed on 5 August 2021).

18. Smart Advocate. Legal Blood Alcohol Content Limits Around the World. 2020. Available online: https://www.smartadvocate. com/News/Blog/blood-alcohol-content-legal-limits (accessed on 5 August 2021).

19. Utah Department of Public Safety. Information About Utah's .05 BAC Law. 2020. Available online: https://highwaysafety.utah. gov/2018/12/11/information-about-utahs-05-bac-law/ (accessed on 5 August 2021).

20. NTSB. Decades of Research Show that.05\% BAC Laws can Save Lives on the Roads. 2017. Available online: https://bit.ly/ 2UZYTTZ (accessed on 5 August 2021).

21. NHTSA. Reaching Zero: Actions to Eliminate Alcohol-Impaired Driving; Safety Report NTSB/SR-13/01; NTSB: Washington, DC, USA, 2013.

22. Abalate, D. Lowering blood alcohol content levels to save lives: The European experience. J. Policy Anal. Manag. 2008, 27, 20-39. [CrossRef]

23. Cassado-Sanz, N.; Guirao, B.; Galera, A.L.; Attard, M. Investigating the risk factors associated with the severity of the pedestrians injured on Spanish crosstown roads. Sustainability 2019, 11, 5194. [CrossRef]

24. Jongen, S.; Vuurman, E.F.P.M.; Ramaekers, J.G.; Vermeeren, A. The sensitivity of laboratory tests assessing driving related skills to dose-related impairment of alcohol: A literature review. Accid. Anal. Prev. 2016, 89, 31-48. [CrossRef] [PubMed]

25. Ramaekers, J.G.; Robbe, H.W.J.; O'Hanlon, J.F. Marijuana, alcohol and actual driving performance. Hum. Psychopharmacol. 2000, 15, 551-558.

26. Burns, M.; Moskowitz, H. Effects of diphenhydramine and alcohol on skills performance. Eur. J. Clin. Pharmacol. 1980, 17, 259-266.

27. Hartman, R.L.; Brown, T.L.; Milavetz, G.; Spurgin, A.; Pierce, R.S.; Gorelick, D.A.; Gaffney, G.; Huestis, M.A. Cannabis Effects on Driving Lateral control with and without Alcohol. Drug Alcohol Depend. 2015, 154, 25-37. [CrossRef] [PubMed]

28. Kenntner-Mabiala, R.; Kaussner, Y.; Jagiellowicz-Kaufmann, M.; Hoffman, S.; Krüger, H.-P. Driving Performance Under Alcohol in Simulated Representative Driving Tasks: An Alcohol Calibration Study for Impairments Related to Medicinal Drugs. J. Clin. Psychopharmacol. 2015, 35, 134-142. [CrossRef] [PubMed]

29. Alali, K.; Stewart, J.S.; Taneja, R.; Nwobi, E.; Malone, K.-J.; Mohammed, M.; Sewart, M.; McQueen, J.; Head, D.; Commissaris, R. Marijuana and alcohol increase crash avoidance reaction time in a driving simulator test at blood concentrations below commonly-used per se 'Cut-offs' for Intoxication. J. Addict. Med. Ther. Sci. 2020, 6, 9-15. [CrossRef]

30. AplusB Corporation. Professional Driving Simulation: DUI Simulator. 2021. Available online: https://aplusbsoftware.com/duisimulator/ (accessed on 5 August 2021).

31. Palumbo, T.J.; Head, D.; Swift, A.; Rumschlag, G.; Ing, J.; Ng, C.; Surducan, M.; Lahoud, E.; Johnson, B.; Mackie, B.; et al. The effects of texting and DUI simulation on driving performance in a driving simulator. J. Ergon. 2015. [CrossRef]

32. Rumschlag, G.; Palumbo, T.; Martin, A.; Head, D.; George, R.; Commissaris, R.L. The effects of texting on driving performance in a driving simulator: The influence of driver age. Accid. Anal. Prev. 2015, 74, 145-149. [CrossRef]

33. Hernandez, O.H.; Vogel-Sprott, M.; Huchin-Ramirez, T.C. Ake-Estrada, F. Acute dose of alcohol affects cognitive components of reaction time to an omitted stimulus: Differences among sensory systems. Psychopharmacology 2006, 184, 75-81. [CrossRef]

34. Plawecki, M.H.; Koskie, S.; Kosobud, A.; Justiss, M.D.; O'Connor, S. Alcohol intoxication progressively impaires drivers' capacity to detect important environmental stimuli. Pharmacol. Biochem. Behav. 2018. [CrossRef]

35. Schweizer, T.A.; Vogel-Sprott, M. Alcohol-impaired speed and accuracy of cognitive functions: A review of acute tolerance and recovery of cognitive Performance. Exp. Clin. Psychopharmacol. 2008, 16, 240-250. [CrossRef]

36. Van Dyke, N.A.; Fillmore, M.T. Distraction produces over-additive increases in the degree to which alcohol impairs driving performance. Psychopharmacology 2015, 232, 4277-4284. [CrossRef] 
37. Innocorp. Eight Hands-On Tools for Your Alcohol Education Program. 2021. Available online: https://www.fatalvision.com/ blog/drunk-driving-prevention-program-resources-tools / (accessed on 5 August 2021).

38. Page, T.; Los Angeles Police Department (LAPD), Los Angeles, CA, USA. Personal communication, March 2021.

39. Rubin, N. Lessons from a Simulator: Set Driving Limit at 0.09\%. Detroit News. 3 February 2021. Available online: https: / /www.detroitnews.com/story/news/local/michigan/2021/02/02/wayne-state-commissaris-bac-drinking-drivingsmirnoff-titos/4177438001/ (accessed on 5 August 2021).

40. Gustin, J.L.; Simons, J.S. Perceptions of level of intoxication and risk related to drinking and driving. Addict. Behav. 2008, 33, 605-616. [CrossRef] [PubMed]

41. Anderson, P.; Chisholm, D.; Fuhr, D.C. Effectiveness and cost-effectiveness of policies and programmes to reduce the harm caused by alcohol. Lancet 2009, 373, 2234-2246. [CrossRef]

42. Peden, M.; Scurfield, R.; Sleet, D.; Mohan, D.; Hyder, A.A.; Jarawan, E.; Mathers, C.D. World Report on Road Traffic Injury Prevention; World Health Organization: Geneva, Switzerland, 2004.

43. Taylor, M.; Infrastructure Bill Would Require Breathalyzers for All New Cars. Forensic Magazine. 2021. Available online: https:/ / www.forensicmag.com/578254-Infrastructure-Bill-Would-Require-Breathalyzers-for-All-New-Cars (accessed on 5 September 2021).

44. Rivara, R.F.; Relyea-Chew, A.; Want, J.; Riley, S.; Boisert, D.; Gomez, T. Drinking behaviors in young adults: The potential role of designated driver and safe ride home programs. Injury Prev. 2007, 13, 168-172. [CrossRef] [PubMed]

45. Hafner, J.W.; Bleess, B.B.; Famakinwa, M.F.; Wang, H.; Coleman, M. The effect of a community crash reenactment program on teen alcohol awareness and behavior. Adolesc. Health Med. Ther. 2019, 10, 83-90. [CrossRef] [PubMed] 